\title{
BRIDGING THE GREAT DIVIDE: MODIFYING TRAUMATIC MEMORIES
}

\section{Mariette van der Merwe}

\section{INTRODUCTION}

Social workers and other professionals in South Africa are constantly challenged by the impact of extreme traumatic events on many of their client populations. This article focuses on a specific area of post-trauma intervention, namely understanding and actively working with traumatic memories. The underlying theoretical paradigm is the constructive narrative perspective (Meichenbaum, 1994) with a focus on more than mere information processing. Account-making and restorying traumatic material into a verbal narrative is core work. Meichenbaum (1994:103) rightly postulates: "People make meaning of their lives by organizing key events into stories which they incorporate into a larger life narrative." The process of meaning-making incorporates each individual's subjective interpretation of events. Psycho-education is a central part of the process to empower traumatised persons to initiate the process of memory shifting.

In the past fifteen years the researcher was involved in post-trauma intervention in various contexts mainly in the Western Cape and Gauteng. Some incidents impacted on groups and communities, such as an incident in Laudium where two young children were crushed by a bus in full view of many learners (Van der Merwe, 1999). In the Dennegeur bus accident (25 August 2005) four people were killed and many injured. This accident was witnessed by many children who were in another bus. This article includes insights gained in the immediate aftermath of this accident, but also in the follow-up intervention in the year after the bus accident. The researcher also intervened after 17 situations where accidents in the construction industry lead to traumatisation in employees. These incidents ranged from collapsed buildings, on-site hi-jack situations and robberies, electrification and motor vehicle crash events. There was intervention in brief incidents, where the duration of impact was merely a few seconds such as robberies, as well as intervention in other situations where chronic domestic violence and sexual abuse continued over years. Trauma in schools was also a focus with the most prominent tragedy being the murder in a toilet of a primary school in the middle of the school day. It is clear from the above that the researcher intervened in many instances of direct and witnessed trauma, with many different age groups and people of diverse culture, background and religion.

As researcher-practitioner the author has a special interest in traumatic memory and with all the above interventions it was a main focus to understand and facilitate the process to shift such memories. This process was enhanced by an ongoing literature review in the field of traumatic stress. In this article literature generated in the late 1980s and 1990s will be purposefully used as those years were an especially prolific time for the emergence of constructs which is still built upon today such as the dual representation model (Brewin, 1989; Brewin, Dalgleish \& Joseph, 1996; Brewin, 2003); cognitive behavioural work and theory of fear structures (Foa \& Kozak, 1986; Foa \& Meadows, 1998), cognitive appraisal work (Janoff-Bulman, 1992) and Meichenbaum's (1994) constructive narrative perspective.

From a research outlook the interventions were significant to the researcher who developed a social work intervention model for traumatised children who witnessed extreme life events (Van der Merwe, 1999). Over the past nine years since completion of the study the 
dissemination of the intervention model was a main focus. This was aided by interactive workshops on post-trauma intervention presented by the researcher to 620 professionals (mainly social workers and psychologists). Monthly supervision sessions with social workers working in the field of trauma also shaped the researcher's conceptualisation of traumatic memories. This article is based on reflexive practice which is described by Potocky-Tripodi and Tripodi (1999:122-123) as: "The reflexive, or research-minded, practitioner uses a variety of research techniques to continually monitor his or her practice and adapt it in response to the data obtained." In this article the focus will be narrowed to working with memories in the context of traumatic stress and this will be illustrated with practice examples.

\section{TRAUMATIC MEMORY}

Traumatic memory is different from ordinary memory firstly because of the location. The hippocampus and amygdala are in the limbic system, placed in the medial regions of the temporal lobe (Hagh-Shenas, Goldstein \& Yule, 1999:147). Wastell (2005:174) describes the function of the hippocampus as having a role in the formation of long-term memory and other cognitive processes associated with learning. These memories are accessible and linear. They can be placed in context and time with more or less stress free recall. Scott (2000:30) explains how the hippocampus locates events in time and space.

Traumatic memories are often located mainly in the amygdala due to many internal processes. Scott (2000:29-30) refers to LeDoux's description of sub-cortical pathways to the amygdala and states: "... these are quick and dirty transmission routes, making for fast responses but failing to distinguish between stimuli such as shots, lightning and slamming doors." The predicament for the traumatised person is that there are seemingly more pathways from the amygdala to the hippocampus than the other way round. Scott (2000:30) states in this regard the difficulty in overriding the amygdala as "... it is as if there is a motorway up to the hippocampus and a backroad downwards." In clinical practice it has been found that self-talk is not always effective in the immediate aftermath of extreme events. Especially with severe with-in event variables traumatised people have reported that logical thinking is not as strong as the primal alarm system of the amygdala. This can be linked to the metaphor of the motorway to the hippocampus versus the backroad to the amygdala. Understanding the processes however offers strong momentum towards incorporating more cognitive processes.

During traumatic exposure the adrenal glands secrete neurohormones or the so-called stress hormones (epinephrine, norepinephrine and steroid stress hormones) (Hagh-Shenas et al., 1999:148). The psyche is protected from overwhelming affect, by encoding the memories of trauma in the more primitive part of the limbic system, namely the amygdala. According to Wastell (2005:170) this small almond-shaped structure of the limbic system is essential in "registering and utilisation of emotion and associated behavioural expressions." Hagh-Shenas et al. (1999:147) recognize the amygdala as the structure of the central nervous system most clearly involved in the screening of emotional significance of incoming stimuli. In this primitive part of the brain, messages taken in by the senses are screened with previous traumatic experience as strong non-verbal template. From the primitive position of the amygdala, alarm reactions are sent out through a network of neurons. Many times in the aftermath of traumatic exposure these alarm reactions are false and based on environmental cues reminiscent of previous traumatic experiences. Such reactivation may lead to startle responses, flashbacks, psychological and physiological arousal and ultimately feed in to hypervigilance. With flashbacks and other forms of re-experience traumatised people may have the same body responses as during incidents. Apart from being encoded in the amygdala it seems 
as if traumatic memories are distributed across a network through the body. Hagh-Shenas et al. (1999:147) refer to the broad connections of the amygdala with cortical sensory systems. Those intervening should be aware of sensory memories, body memories and also the emerging information on cell memories. It is clear that the amygdala has a powerful effect on the overall functioning of traumatised people.

Being so primitive, the amygdala does not place memories in an ordered, linear and recallable format. It is free floating, frameless and clients have often reported that such memories feel recent even though the event(s) may have occurred years ago, which would also imply that such memories may be timeless.

Traumatic memories are typically fragmented, intrusive and linked to the senses in a literary alarming way. Cues picked up by the senses may send the amygdala as alarm system into a frantic cauldron of hyper alertness and anxiety. In the aftermath of traumatic exposure, this amygdala as alarm system is prone to malfunction and to give false alarms. This will keep traumatised victims in an energy-tapping state of high alert and vigilance. Trauma related sensations and affect can translate into automatic negative thought patterns based on the experience, especially related to hyper-vigilance i.e. with thoughts such as: "My father is not here to pick me up; he must have been in an accident." Traumatic memory has been described as a puzzle where the frame remains intact, but the pieces are scattered. Dealing with such memories implies the stirring up of "...memories and feelings that had begun to settle in maladaptive ways" (Monahon, 1993:168). There may be a time skew in episodic memories and also emotional detachment.

A single traumatic event may reflect various frightening smaller memories and complex traumatic moments. Pynoos and Nader (1993:537) caution that traumatic events are not recalled as single episodes, but that multiple traumatic episodes are inferred within a single event. Monahon (1993:4) supports this by likening memories of traumatic events to " $a$ snapshot of the event that freezes certain visual and sensory information into a lasting image." This concurs with what Pynoos and Nader (1993:537) refer to as anchor points or memory markers that influence memory organisation and recall strategies. Memory markers may offer notable clues to significant clinical issues. After witnessing a motor vehicle accident, children will for instance focus on anchor points such as perceptual experience, injuries of victims, witnessing death or near death, sounds of impact, dismembered body parts, blood, noise, rescue operations and even seemingly non-traumatic aspects such as birds flying over, which can become traumatic reminders of the incident. All these memory markers reflect different angles of a single traumatic event.

Clients have referred to traumatic memories by saying that it is constantly flickering unsteadily into their thoughts. Someone likened it to a video that is continually playing and that she cannot find the switch to put it off. Someone else said that it is as if she constantly has a video in her head, playing over and over, and that she does not succeed in taking it back to the video store. Another client described the energy-tapping rumination, hyper-vigilance and futility of the intrusion in the following: "You are walking and moving and thinking about it all the time, but when you look down you have walked a hole in the ground." This is supported by another client statement: "My life is a broken wheel; when it reaches the crack it gets stuck."

Brewin et al. (1996) developed Brewin's dual representation theory and applied it to PTSD. Amygdala-positioned memories are called situationally accessible memories (SAM'S) and such memories are reactivated by many trauma-related situational cues (Brewin et al., 1996). 
However, such memories cannot be directly accessed or edited as they are mainly situationally controlled. When there is limited awareness of such processes by traumatised persons, they may be left with an enduring sense of lack of control and high levels of anxiety. According to Zoellner and Bittenger (2004:149) such traumatic material is non-elaborated and disconnected with certain elements intruding into consciousness with constant rumination or intrusive reexperience. According to Herman (1997:37) the traumatic moment becomes encoded in "...an abnormal form of memory, which breaks spontaneously into consciousness, both as flashbacks during waking states and as traumatic nightmares during sleep." Repression of situationally accessible memories is not a passive process. It is energy consuming to keep material out of awareness as stated by Bisbey and Bisbey (1998:34): "It takes a certain amount of energy to deal with any given situation, day-to-day. When a person does not deal with a situation, but rather represses or dissociates it, he must keep some attention in that area to keep the disturbing material out of awareness." Van der Kolk (1997:252) uses the terms implicit and explicit memories and states that: "In some people the memories of trauma may have no verbal (explicit) component at all; the memory may be entirely organized on an implicit or perceptual level, without an accompanying narrative about what happened." Such implicit (SAM'S) memories entail vivid fragmented sensations, images and feelings, but are not linear, whereas explicit memory processes (VAM'S) work with verbalized narratives.

Verbally accessible memories (VAM'S) can be “... consciously edited and can interact with the rest of the autobiographical memory base" (Zoellner \& Bittenger, 2004:149). VAM memories are linear and sequence of events is sorted out. These memories can be connected with reference to thoughts, affect, behaviour, body reactions and perceptual aspects. Verbally accessible memories will probably be narrated by the client and elements of the cognitive appraisal model of Janoff-Bulman (1992) can help them to integrate the events into a new world view.

Giarratano's (2004:107-114) two-world's model of trauma is a useful concept that can be linked to the above information as part of psycho-education. Traumatised persons are alerted to ways in which trauma exposure can alter their world views. New rules emerge from the trauma world and these rules are not always conducive to ongoing living in the now world or current reality. For a victim of a public transportation accident the trauma world rule connects with avoidance to lead to the perception that public transport is dangerous. However, in the now world or current reality it may be the client's only means of transport to work or for recreation. If he or she adheres to the trauma world rule the quality of life and means of support will be compromised. When constructing the verbal narrative of trauma, it is helpful to list trauma world rules emerging from the traumatic experience and how these impact on the rules of the now world.

A main aim of post-trauma intervention is to bridge the divide between amygdala and hippocampus and to shift memories to where there is a conscious awareness of the processes involved as well as access to the correct sequence of the event(s). Meichenbaum (2000:58) talks about a collaborative co-constructive approach whereby a new narrative is constructed. Intervention should focus on situationally accessible memories through creative means such as art work, drawings of trauma scenes, creative writing and also by raising awareness of triggers and actively mapping triggers. These memories should be verbalised and reconstructed. 


\section{MEMORY SHIFTING}

Although the focus in this section is on the components of memory shifting, this should occur within a change process which would ideally be based on integrative counselling, such as the sequentially planned integrative counselling model (SPICC model) as described by Geldard and Geldard (2002:59-69). The value of this model is that it integrates therapeutic approaches. In the process there will be place for client-centred interventions, gestalt therapy, narrative therapy and cognitive behaviour interventions amongst others. Each individual client with their particular process will determine the therapeutic approach utilized in a particular phase. Through these phases of the helping goals will fluctuate between process and content goals. During post-trauma intervention aimed at memory shifting it is crucial that the helping process be constantly monitored and assessed also with the particular client. Contracting is an important part of the process as the work of memory shifting may lead to resistance when confrontation or withdrawal ruptures occur. Such ruptures may be statements or behaviour and can also be part of the helper's process due to the severe content of traumatic memories (Draucker \& Martsolf, 2006:115-119). Possible ruptures and resistance should be pre-empted and form part of the ongoing discussions.

Some core tasks and components of the process of memory shifting and construction of verbal narratives are the following:

- Clients should understand the process and be willing to engage in a journey where rumination, intrusion and other reactions might intensify before improving.

- A reference to the trauma should be made as early as possible in the intervention process.

- Psycho-education and the use of parallel narratives lead to an almost detached understanding of the effects of the trauma which may also indicate that their responses are to be expected and that they are not going mad.

- Anxiety management with controlled breathing should be an integral part of intervention to enable clients to moderate their stress levels.

- Creating awareness of distress levels by utilising SUD Scales (Subjective Units of Distress) can lead to strategies such as giving clients control over content in sessions (Williams \& Poijula, 2002:41-42). The researcher gives clients the option to stop trauma-related discussions at any time. Sometimes they use tokens such as rattles to indicate high levels of distress. The powerlessness and helplessness which is so ingrained in extreme events must not be repeated in intervention processes.

- Both client and helper should understand the dialectic nature of trauma with the oscillation between re-experience and repression. Herman (1992:176) rightly states that a "safe passage" should be negotiated between the "twin dangers" or dialectic of opposing psychological states, namely constriction and intrusion. Trauma integration is impeded by avoidance of trauma memories. On the other hand too rapid reconstruction may be overwhelming and damaging. Herman (1992:181) describes this frightening oscillation as follows: "Denial of reality makes them feel crazy, but acceptance of the full reality seems beyond what any human being can bear." Surfacing and processing of trauma memories and other related material is a main aim of intervention, provided that helpers note how denial may initially serve as an adaptive measure and breaking it down prematurely may be harmful. Intrapsychic processing of trauma is the core task of intervention.

- Creative interventions such as trauma scene drawings seem to be useful in accessing the wordless situationally accessible memories. 
- Trauma-related props can be used on trauma scene drawings to show rather than to tell the facts of extreme events.

- Discussions do not have to start with exploration of facts as in more traditional debriefing or exposure models. In line with emotion-focused intervention (Wastell, 2005) the emotions of the traumatised person can open trauma-related discussions. A body map can be used to indicate body reactions with particular emotions and this can be traced back to triggers and the facts of extreme events. Typical questions would be: "Tell me about any profound or painful emotions experienced in the past week. Can this be linked to your experience?" As clinical detective the helper then plots triggers and the effects of such triggers. It has been noted in clinical practice how triggers often lead to unpacking of traumatic material on SAM's level. Using the here-and-now of the therapeutic situation is helpful when facial expression, tone of voice and other non-verbal cues can be used to ask the client to elaborate on the mind work in the moment.

- Different colours can be used on drawings of trauma scenes to indicate facts, thoughts, affect behaviour, body response and the different senses including spatial awareness. The colours can be extended to trigger mapping.

- Clients can be helped to identify repetitive thoughts and automatic negative thinking (ANTS) (Giarratano, 2004).

- The focus should not be merely on the trauma story but also on the alternative story which highlights coping and wisdom gained in line with the work of Mitchell (2005). The approach should be hopeful, keeping in mind possible iatrogenic effects. Clients are suggestible in the aftermath of extreme events and helpers must be careful not to create expectations of severe reactions still to come.

In the immediate aftermath of extreme events, traumatised people typically have muddled representations of events which may intrude in the form of flashbacks. An eight-year-old boy who witnessed how his younger brother was knocked down and killed by a car while they were riding their bicycles (Van der Merwe, 1999:284) made a drawing in the first week after the incident which clearly depicts a non-linear and muddled representation of the event (possibly a SAM's presentation). He drew his brother's head very small on a long neck (his brother had serious head injuries which were witnessed by the eight-year-old boy). He included a monstertype figure with sharp teeth in this drawing and also an image of an angry angel with long nails. There was also a ghostlike figure and in the corner of the drawing was an onlooker, possibly representing himself. He could not discuss this drawing, but engaged in post-trauma play where he repetitively played out what happened. As the post-trauma intervention progressed, he verbalised his experience and made a series of drawings on which he commented and clarified the facts of the extreme event, his emotions, thoughts, sensory experience, his behaviour during and after the extreme event and his body reactions. These drawings and discussions were much more linear and organised than the initial representation. At this point the traumatic memories were verbally accessible. The child could also engage in activities focused on bereavement. Post-trauma intervention in this case aided the process of memory shifting from SAM's (situationally accessible) to VAM's (verbally accessible). When this child entered the process, the intrusion and rumination were clear from his reaction to environmental cues. In the first session the tape recorder made a sudden sound when the tape ended. The child showed an exaggerated startle response to this sound. It was later understood how the sound of the crash was especially intrusive. Reactions to triggers offer some insight into possible SAM's material. 
The wordless quality of traumatic memories is illustrated by the following case example. During the 7th session of intervention a 10 year-old child wrote an article on her traumatic experiences on the computer. She was raped by two family members. Her first sentence is: "The people do horrible things to Lucy." (Fictitious name is used). She then requests the social worker to type and she dictates as follows:

Belle nebo cileka chaba, Mary. Actually, Mary is me. Se blleblena bigga tapo chapo lekka he moto Mary mamba slep chaba. Abbo chemba Mary. Abbo Chemba Lucy.

This seems like a traumatized child struggling to bridge the great divide between situationally accessible traumatic memories and ordinary thinking. It seems to be more than mere regression. She is struggling to put words to body memories and sensory memories. She is trying to give words to the unspeakable; to the horror almost too big to utter. She is fluctuating between Lucy and Mary - Mary being her second name. This child showed progress in formulating a narrative account of the trauma especially because of her reliance on SUD scales and a rattle which she could use to stop trauma related discussions. Post traumatic play was a crucial part of intervention, initiated by the child. At times she said that she did not want to talk about the extreme events, but because of the intrusive nature of memories, she almost could not help herself from talking about the events. Due to the seriousness of the trauma the process of memory shifting in her case will probably be a long-term endeavour.

Scott (2000:30) delineates a therapeutic task as follows: “... to try to gain conscious wilful control of the sub-cortical pathways to the amygdala to whatever extent is possible, and to try to 'soothe' the amygdala with corrective information from the cortex." The ultimate goal is to override the faulty alarm system of the amygdala with cognitive processes, logical thinking and the ability to regulate the traumatic material by placing it in appropriate context and time frame with a verbal trauma narrative.

\section{CONCLUSION}

Traumatic memories in implicit memory storage are not controlled, mastered or integrated. The imprints of traumatic events in the amygdala remain recent and untouched by passage of time. The alarm system of the amygdala is overly alert and may lead to ongoing hyper-vigilance and arousal. The following metaphor of Giarratano (2004) illustrates the complexity of memory work in the context of trauma: “... addressing painful memories is like climbing out of hell on an aluminium ladder. One can choose to stay in hell trying to shelter from the flames, or make a run for it, climbing the ladder to get out. Touching the ladder burns however, because it's right in the middle of the flames, but as we climb, the heat reduces, and eventually we are able to get out of hell. This process happens also with traumatic exposure - at first 'touching' the memory hurts, and holding onto it is very painful - but the more we stay with it, the more the pain decreases, until eventually we have climbed out of hell" (Giarratano, 2004:237). In clinical practice it has been observed by the author how psycho-education regarding the processes described here, as well as the opportunity to actively work with memories in a controlled, safe therapeutic environment enables traumatised people to verbalise their experiences and to report more control over the memories.

Clearly traumatic memories can cause serious discomfort and distress. Especially with acute events there is a picture clear quality to the memory fragments, but limited structure, sequence and order. Not grounded in the usual time conceptions of the other brain areas, it seems to many traumatised victims as if traumatic exposure happened recently, even if in reality it occurred months or even years ago. Traumatic memories seemingly have a tendency to 
override and overrule the memory function of the brain and not to take its place in the historical timeline of the traumatised. Creative intervention should focus on the memory content and shifting of memories from the primitive amygdala to the more advanced hippocampus for a new and more manageable narrative to emerge.

\section{BIBLIOGRAPHY}

APPELBAUM, P.S., UYEHARA, L.A. \& ELIN, M.R. 1997. (eds) Trauma and memory: clinical and legal controversies. New York: Oxford University Press.

BISBEY, S. \& BISBEY, L.B. 1998. Brief therapy for Post-Traumatic Stress Disorder. Traumatic incident reduction and related techniques. New York: John Wiley \& Sons.

BREWIN, C.R. 1989. Cognitive change processes in psychotherapy. Psychological Review, 96:379-394.

BREWIN, C.R., DALGLEISH, T. \& JOSEPH, S. 1996. A dual representation theory of posttraumatic stress disorder. Psychological Review. 103:670-686.

BREWIN, C.R. 2003. Post-traumatic Stress Disorder: malady or myth? London: Yale University Press.

DRAUCKER, C.B. \& MARTSOLF, D.S. 2006. Counselling survivors of childhood sexual abuse $\left(3^{\text {rd }}\right.$ ed). London: Sage Publications.

FOA, E.B. \& KOZAK, M.J. 1986. Emotional processing of fear: exposure to corrective information. Psychological Bulletin, 99:20-35.

FOA, E.B. \& MEADOWS, E.A. 1998. Psychosocial treatments for post-traumatic stress disorder. In: YEHUDA, R. (ed) Psychological trauma. Washington: American Psychiatric Press: 179-199.

GELDARD, K. \& GELDARD, D. 2002. Counselling children. A practical introduction $\left(2^{\text {nd }}\right.$ ed). London: Sage Publications.

GIARRATANO, L. 2004. Clinical skills for treating traumatised adolescents. Evidence based treatment for PTSD. Australia: Talomin Books.

HAGH-SHENAS, H., GOLDSTEIN, L. \& YULE, W. 1999. Psychobiology of post-traumatic stress disorder. In: YULE, W. (ed) Post-traumatic stress disorders. Concepts and therapy. New York: John Wiley \& Sons.

HERMAN, J.L. 2001. Trauma and recovery (rev ed). USA: Basic Books.

JANOFF-BULMAN, R. 1992. Shattered assumptions. Towards a new psychology of trauma. New York: The Free Press.

MEICHENBAUM, D. 1994. Treating post-traumatic stress disorder. A handbook and practice manual for therapy. New York: John Wiley \& Sons.

MEICHENBAUM, D. 2000. Treating patients with PTSD: A constructive narrative approach. National Centre for PTSD Clinical Quarterly, 9(4):55-59.

MITCHELL, S. 2005. Debriefing after traumatic situations - using narrative ideas in the Gaza strip. The International Journal of Narrative Therapy and Community Work, (2):23-28.

MONAHON, C. 1993. Children and trauma. A parent's guide to helping children heal. Toronto: Lexington Books. 
POTOCKY-TRIPODI, M. \& TRIPODY, T. (eds) 1999. New directions for social work practice research. Washington: NASW Press.

PYNOOS, R.S. \& NADER, K. 1993. Issues in the treatment of posttraumatic stress in children and adolescents. In: WILSON, J.P. \& RAPHAEL, B. (eds) International handbook of traumatic stress syndromes. New York: Plenum Press: 535-550.

ROSEN, G.M. (ed) 2004. Post-traumatic stress disorder. Issues and controversies. West Sussex: John Wiley and Sons.

SCOTT, M.J. 2000. Assessment and conceptualization. In: SCOTT, M.J. \& PALMER, S. (eds) Trauma and post-traumatic stress disorder. London: Cassell: 15-32.

SCOTT, M.J. \& PALMER, S. (eds) Trauma and post-traumatic stress disorder. London: Cassell.

VAN DER KOLK, B.A. 1997. Traumatic memories. In: APPELBAUM, P.S., UYEHARA, L.A. \& ELIN, M.R. (eds) Trauma and memory: clinical and legal controversies. New York: Oxford University Press.

VAN DER MERWE, M. 1999. A social work practice model for young children traumatised by witnessing sudden, unexpected extreme life events. Stellenbosch: University of Stellenbosch. (Unpublished DPhil Dissertation)

WASTELL, C. 2005. Understanding trauma and emotion. Dealing with trauma using an emotion-focused approach. New York: Open University Press.

WILLIAMS, M.B. \& POIJULA, S. 2002. The PTSD Workbook. Oakland, California: New Harbinger Publications.

ZOELLNER, L.A. \& BITTENGER, J.N. 2004. On the uniqueness of trauma memories in PTSD. In: ROSEN, G.M. (ed) Post-traumatic stress disorder. Issues and controversies. West Sussex: John Wiley and Sons: 147-162.

Dr Mariette van der Merwe, Department of Social Work, University of Stellenbosch, Stellenbosch, South Africa. 